\title{
Knowledge, Attitude and Awareness of Diabetes Nutrition in Physicians
}

\author{
Sharad Kumar $^{1 *}$, Mahesh Abhayankar ${ }^{2}$ and Rohit Malabade ${ }^{2}$ \\ ${ }^{1}$ Professor in Medicine, Eras Lucknow Medical College, India \\ ${ }^{2}$ USV Pvt Ltd, India
}

Submission: November 13, 2018; Published: January 28, 2019

*Corresponding author: Sharad Kumar, Professor in Medicine, Eras Lucknow Medical College, Lucknow, India

\section{Abstract}

Background and objective: Diet management is the integral part of diabetes. A regular and balanced diet helps in a better glycemic control in type 1 and Type 2 diabetes. The objective of this survey was to examine the current dietary practices and to get a view of the current practice of doctors towards advising diet to their diabetic patients.

Methods: A survey form consisting of 21 questions, was specifically designed to understand doctor's view on recommended or discouraged diet for diabetic patients. The survey form was circulated to the doctors across various geographical locations of India. The obtained response was analyzed and the results were expressed in terms of percentages based on the number of responses obtained.

Results: The survey included 644 consulting physicians who responded to the distributed survey questionnaire. Majority of the doctors selected $1800-2200$ calorie and 1800 calorie diet for healthy men and women respectively and opined that restricting the calorie intake can help in weight reduction as well as a better control of glycemia in diabetic patients. The rice intake should be discouraged in diabetic patients as per $46.7 \%$ of doctors and $48.6 \%$ of doctors believed that potato, sweet potato, and carrots should be avoided by patients with diabetes. $61.3 \%$ of doctors opined about avoiding mangoes, banana and grapes for diabetic patients. Surprisingly instead of ripe fruits, $26.4 \%$ of doctor's recommended all unripe fruits. Seasonal fruits such as apple, guava, carrots were suggested only up to 200 gm by $46.2 \%$ of doctors and up to 400 gm by $30.3 \%$ of doctors. Most doctors preferred that dietary fats should only contribute to about $10 \%-20 \%$ of calories and preferred it to be from olive oil. Egg should be consumed without egg yolk as per $60.3 \%$ of doctors' opinion. Artificial sweeteners can be taken as they are considered safe in moderate amount as preferred by 51.6\% doctors. In this survey, majority of the doctors agreed on avoiding sweet items and food item with high glycemic index.

Conclusion: A good proportion of qualified physicians lack sufficient knowledge of important aspects in nutrition: ideal calorie intake for men and women; glycemic index of fruits and vegetable; recommendation of ripe/unripe fruits or fruit juices; intake of sweets, artificial sweetener and cane sugar. This highlights the need of better training for first-line health-care providers and we recommend dietary management to be included in medical education at all specialty ladders.

Keywords: Diet; Fruit juice; Artificial sweetener; Calories; Unripe Fruits; Dietary fats; Diabetic patients; Glycemic; Fat; Carbohydrate metabolism Glucose homeostasis; Anti-diabetic drugs; Insulin; Saturated fats; Nutritional therapy

\section{Introduction}

Diabetes mellitus is a global public health problem with increasing prevalence and puts a significant financial burden on patient and health-care system. According to IDF 2017, India is home to the second largest number of adults living with diabetes worldwide. One of the goals of diabetes management is to improve fat and carbohydrate metabolism in the tissues and maintain whole-body glucose homeostasis with regular exercise, healthy diet and medicines. Medical nutrition therapy is an integral part of effective diabetes management which advocates the consumption of fruits, cereals, vegetables, milk and milk products [1]. An appropriate diet and exercise in diabetic patient improve glycemic control and insulin sensitivity and decreases the need for oral anti-diabetic drugs or insulin. The optimal diet for diabetes still remains a debatable issue; however dietary guidelines recommend increasing the consumption of fruits and vegetables and decreasing the daily consumption of saturated fats [2].

The study by Ahmadi et al suggested that physicians have inadequate knowledge related to nutrition, which revealed that $13.1 \%$ doctors had mediocre and $86.9 \%$ doctor had poor nutrition knowledge [3]. While, another study showed that 25\% doctors found it difficult to identify patient in need of nutritional therapy, 39\% lacked techniques for identifying malnourished 


\section{Current Research in Diabetes \& Obesity Journal}

patients, and $53 \%$ found it difficult to calculate the patients' energy requirement and $66 \%$ lacked knowledge of national guidelines for clinical nutrition [4]. Similarly, a questionnairebased survey by Hu SP et al showed that physicians did consider nutrition to be important in their personal and clinical practice and $78 \%$ agreed with the statement that nutrition consultation should be a part of health care delivery [5]. This dietary survey was conducted to analyze knowledge and understanding of the dietary regimes being advised to type 2 diabetes patients in Indian settings.

\section{Materials and Methods}

An anonymous survey questionnaire was designed to assess the physicians' self-reported behavior on specific food items that needs to be included or excluded from the diet of the diabetic persons. The survey questionnaire consisted of 21 multiplechoice questions. The first three questions collected information on the average calorie intake in men and women, and importance of calorie reduction in diabetic patients. The next two questions focused on vegetables and cereals to be avoided in diabetic patients. Further, six questions focused on consumption of fruits, fruit juices, ripe, seasonal and dry fruits and cane sugar in diabetic patient. The next three questions consisted of amount of dietary fat recommended, preferable source of dietary fat. Finally, last six questions were based on consumption of milk/ tea/coffee, sweet substances, eggs and cholesterol content of diet (Table 1).

Table 1: Doctors' opinion about egg consumption for diabetics.

\begin{tabular}{|c|c|}
\hline Assessment & Doctors N (\%) \\
\hline Eggs should be avoided & $45(7.5)$ \\
\hline $\begin{array}{c}\text { As all diabetics are on statins so } \\
\text { this much of cholesterol does not } \\
\text { matter }\end{array}$ & $81(12.6)$ \\
\hline $\begin{array}{c}\text { Cholesterol of eggs is generally } \\
\text { found to be harmless }\end{array}$ & $94(14.6)$ \\
\hline $\begin{array}{c}\text { Egg yolk containing cholesterol } \\
\text { should not be consumed }\end{array}$ & $311(48.3)$ \\
\hline
\end{tabular}

The survey questionnaire was given to doctors across various geographical locations of India and duration of $20 \mathrm{~min}$ was allocated for completing the questionnaire. Most of the questions needed single response, while particular questions needed multiple responses. The completed forms were collected, and further descriptive analysis was performed. The results were expressed in percentages based on the responses for each question. There was voluntary participation of all the doctors in the survey and no incentives were provided for their participation.

\section{Results}

\section{Population characteristic}

The study included 644 consulting physicians which participated in the diet survey consisting of 21 survey questionnaires.

\section{Calorie intake}

Table 2: Average calorie requirement per day (kcal) by healthy Indian men and female.

\begin{tabular}{|c|c|c|c|c|}
\hline \multirow{2}{*}{ Calories } & \multicolumn{2}{|c|}{ Female } & \multicolumn{2}{c|}{ Male } \\
& No. & \% & No. & $\%$ \\
\hline 1800 & 170 & 26.4 & 211 & 32.8 \\
\hline 2000 & 282 & 43.8 & 133 & 20.7 \\
\hline 2200 & 148 & 23 & 197 & 30.6 \\
\hline 2400 & 29 & 4.5 & 93 & 14.4 \\
\hline $\begin{array}{l}\text { Not An- } \\
\text { swered }\end{array}$ & 15 & 2.3 & 10 & 1.5 \\
\hline
\end{tabular}

The results revealed that most doctors (84.1\%) believe that the average calories required per day by an index healthy man is 1800 - 2200 calorie per day, while for a woman, the average calories required per day reported is 1800 , by $43.8 \%$ of doctors (Table 2). The ideal calorie requirement however, as recommended by NIN for an index man and woman is 2400 calorie and 2100 calorie respectively [6]. This gap in the knowledge often leads to erroneous dietary recommendation. Similarly, $77.5 \%$ of doctors believed that calorie reduction helps in decreasing weight, cholesterol and triglycerides in the management of diabetic patient, which is true for overweight diabetic patients, but will not be helpful in a normal weight patient [6], this was opinion of about $77 \%$ of physicians.

\section{Cereals and vegetables}

Rice and maize should be discouraged in diabetic patients as per $46.7 \%$ and $11.0 \%$ of doctors respectively. $25.6 \%$ of doctors opined that total intake of the cereals should be reduced. Similarly, $48.6 \%$ of doctors think that potato, sweet potatoes and carrots should be avoided by diabetic patients. While $22.2 \%$ and $19.1 \%$ doctors suggest that potato and sweet potato respectively, need to be avoided. However, guidelines only recommend daily calories intake for diabetes patient and lacks restriction about the individual food items such as rice or maize [7].

\section{Fruit intake}

Table 3: Profile of dry fruits in diabetic person.

\begin{tabular}{|c|c|c|}
\hline \multirow{2}{*}{ Assessment } & \multicolumn{2}{|c|}{ Doctors } \\
\cline { 2 - 3 } & No. & \% \\
\hline Should be avoided & 144 & 22.4 \\
\hline Can be taken & 336 & 52.2 \\
\hline Very beneficial & 83 & 12.9 \\
\hline Not Answered & 85 & 13.2 \\
\hline
\end{tabular}

Whole fruits such as mangoes, banana and grapes should be avoided in diabetic patients, was suggested by $61.3 \%$ of doctors. Instead of ripe fruits, $73.6 \%$ of doctors recommend all unripe fruits to diabetic patients. Seasonal fruits such as apple, guava, carrots are recommended only up to $200 \mathrm{gm} /$ day, by $46.3 \%$ of doctors and up to $400 \mathrm{gm} /$ day by $30.3 \%$ of doctors. Dry fruits are recommended by $52.2 \%$ of doctors only (Table 3 ). Fresh fruit 
intake should be encouraged in all diabetic patients, as their relatively low glycemic index does not add to a significant surge in glycemia. Around $47.7 \%$ of doctors felt that fruit juice such as orange, pomegranate or mango juice should be avoided, while $8.5 \%$ felt that there is no need to avoid the same and $22.8 \%$ specified avoidance of mango juice.

Fruit juices are a rich source of calories without fiber and with relatively high glycemic index. Hence, it is better to avoid fruit juices in diabetic patients. It is also suggested that a diabetic patient should consume the whole fruit with skin, instead of fruit pulp /juices. Ideally, minimum of four or five servings per day of fruits and vegetables is recommended (i.e., approximately 400-500 g/day including three vegetable and two fruit portions [e.g., $100 \mathrm{~g}$ of (one katori) raw vegetables (e.g., cauliflower, brinjal, etc.) $=20-30 \mathrm{Kcal} ; 100 \mathrm{~g}$ of fruit e.g., one apple=59 Kcal]) [8]. Dry fruits also should be made a part of daily diet wherever possible, as these encourage a rise of HDL, are a very rich source of high-quality protein and do have a very low glycemic index and therefore do not add to rising glycemia.

\section{Cane sugar}

Around $46.0 \%$ of doctors believed that cane sugar should be stopped completely in diabetic person. While the glycemic index of cane sugar is only $40 \%$ as compared to wheat (70\%), but it's contribution in blood glucose rise after its consumption is insignificant. Hence it is suggested to diabetic patient to avoid sugars in totality [7].

\section{Dietary fats}

Responding to the requirement of dietary fats in diabetic patients, whether it should contribute $10 \%, 20 \%$ or $30 \%$ of calories, the response was $30.7 \%, 23 \%$ and $10.1 \%$ of doctors respectively. A healthy and well-balanced diet which is recommended for all, as well as to all diabetic patients, should include fats and oils in such a way that they contribute $30 \%$ of their daily calories [9]. Unfortunately, however only $10 \%$ of doctors believe and recommend this to their diabetic patients. The physician fraternity should introspect therefore that by recommending a very low-fat diet, are they actually not recommending an unhealthy and harmful diet to their patients. Around $30.3 \%$ of doctors suggested that the source of dietary fat should be olive oil rather than ghee, canola/safflower/ground nut oil, while $29 \%$ of doctors selected that source should be a combined use of all the above oils in almost equal proportion. The best dietary fat would be olive oil, as preferred by $40.7 \%$ of doctors. Olive oil is rich in monounsaturated fatty acids and is definitely a healthy choice, but it doesn't go well with Indian culture and traditional dietary choices, besides being expensive [10]. Further use of Olive oil alone as a dietary fat is also not recommended, probably it will not be able to provide all the essential amino acids in the proportion needed by body.

The general recommendation as per various guidelines is that everyone, except for few who have a raised LDL, including a diabetic person. should consume a combination of Saturated, Mono unsaturated and Polyunsaturated oils in almost equal proportion, in their diets. For individuals, having low-density lipoprotein cholesterol of $>100 \mathrm{mg} / \mathrm{dL}$, saturated fatty acids should be $<7 \%$ of total energy intake/day [11]. There should therefore be no reason why fats like butter, sunflower oil or mustard oil be not recommended to our diabetic patients in the permissible quantities, besides olive oil, if acceptable to the person.

\section{Milk/tea/coffee/beverages}

Around $53.7 \%$ of doctors preferred to avoid tea/coffee with sugar, carbonated soft drink and lassi (sugar sweetened yoghurt) in the diabetic patient. Similarly, $43.6 \%$ of doctors advised diabetic patient to eat curd but avoid extra sugar while, $23.4 \%$ of doctors suggested curd with artificial sweetener. Milk administered to the diabetic patient should be fat free as advised by $42.5 \%$ of doctors. Further, studies are data to convince that increased intake of dairy products was found to be associated with lower measures of body fat, including waist-to-hip ratio. A similar relationship was observed for total milk consumption, and for yogurt [12]. These results are supported by a recent review, where authors concluded that increased consumption of dairy products has a modest, positive effect with respect to body weight and body fatness [13].

\section{Sweet intake}

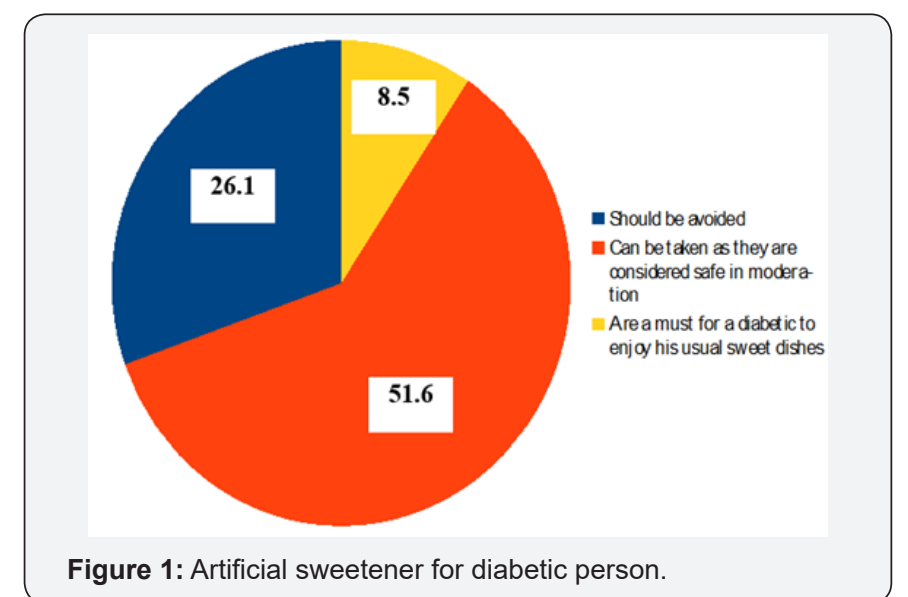

Sweet food items such as cake, jalebi, and sweet biscuits should be avoided as per the belief of $79.7 \%$ of doctors. The intake of sweets as long as their calorie content is within the recommended quota are absolutely harmless and therefore there seems absolutely no reason to restrict these items from the daily diet of all diabetic persons. This absolutely unjustified restriction generates a lot of anxiety and guilt feeling, amongst the patients and their families, and may be a significant contributor, of often associated depression in diabetic patients. Around $60.8 \%$ of doctors opinioned that artificial sweeteners can be taken as they are considered safe in moderation (Figure 1). While these agents so far are being considered in "generally regarded as safe (GRAS)" category, and therefore can be allowed in moderation. 


\section{Egg and cholesterol content}

As one egg contains $300 \mathrm{mg}$ of cholesterol, which is equivalent to the maximum dietary limit of cholesterol per day, one egg with yolk, per day can be considered to be reasonably safe for most non-obese diabetic patients.

\section{Discussion}

Self-discipline and dietary management is a key step, according to American Diabetes Association in the management of diabetes. Skilled management needs knowledge about nutritional aspects, medications and possible diabetes related complications. The study results indicate that physicians are generally aware of information which has been publicized in the medical and lay press but have a poor knowledge of other important topics in nutrition which have been given less importance. Overall, the results of this study indicate that there is serious lack of knowledge in physician as far as dietary recommendations to a diabetic patient are considered. Many physicians do not have the expertise to properly advise their patients on important aspects of the role of nutrition in prevention, and treatment of disease, which reflects the low priority given to the subject in medical schools and in continuing medical education sessions. The patients are also often ill-advised about consumption of dairy products also. An unnecessary restriction about its consumption often becomes counterproductive and adds to malnutrition.

Nutrition is important in managing diabetes, hence, the dietary practice of doctors should match the standard guideline recommendations. In this survey, majority of the doctors agreed on avoiding sweet items, food items with high glycemic index and egg yolk, which was not quite true as per the standard guidelines. Let us propagate the belief that a healthy, well balanced and nutritious diet which is good for everybody is good for all diabetic persons as well. However, an obese diabetic person should reduce his calories like any other non-diabetic obese person.

What is more important to be stressed, however in view of possible hypoglycemia, all diabetic persons, especially who are on insulin or sulphonylurea, should be careful about taking their carbohydrate containing meals at regular time intervals every day [14].

\section{Conclusion}

The current survey presents that the practicing physicians generally believe in the importance of dietary regime and recommend a strict and similar diet to almost every diabetic patient in India. By contrast, a sizable proportion of physicians lack sufficient knowledge of important aspects of nutrition: ideal calorie intake for men and women; glycemic index of various food items including fruits and vegetables; intake of sweets, artificial sweetener and cane sugar. The study clearly indicates that physicians need more training in nutrition. Accordingly, nutrition needs to be properly integrated into the medical school curriculum. Hence, we recommend dietary management to be included in medical education at all specialty ladders. There is a need for interventions which includes nutrition education programs or awareness programs to promote health and prevent diabetes complications in the future.

\section{Limitation}

The limitation of the study includes that the non-responding doctors may have a knowledge, practice patterns and perceptions different from the respondents. There is diversity in dietary pattern across India. The wide regional distribution of the sample size may help mitigate some of these concerns. The current survey forced the respondent to choose a right answer and not allowed multiple selections.

\section{References}

1. Dämon S, Schätzer M, Höfler J, Tomasec G, Hoppichler F (2011) Nutrition and diabetes mellitus: an overview of the current evidence. Wien Med Wochenschr 161(11-12): 282-288.

2. Stephenson EJ, Smiles W, Hawley JA (2014) The relationship between exercise, nutrition and type 2 diabetes. Med Sport Sci 60: 1-10.

3. Ahmadi A, Ershad M, Givzadeh H, Mohammad-Beigi A (2009) General physicians knowledge about nutrition in Shiraz, Iran. Pak J Biol Sci 12(13): 981-985.

4. Mowe M, Bosaeus I, Rasmussen HH (2008) Insufficient nutritional knowledge among health care workers? Clin Nutr 27(2): 196-202.

5. Hu SP, Wu MY, Liu JF (1997) Nutrition Knowledge, attitude and practice among primary care physicians in Taiwan. J AM Coll Nutr 16(5): 439442 .

6. (2011) Dietary guidelines for Indians - A manual. National institute of nutrition. 2: 1-179.

7. (2018) Lifestyle Management: Standards of Medical Care in Diabetes. ADA Diabetes Guidlines. Diabetes Care 41(1): S38-S50.

8. Misra A, Sharma R, Gulati S, Joshi SR, Sharma V, et al. (2011) Consensus Dietary Guidelines for Healthy Living and Prevention of Obesity, the Metabolic Syndrome, Diabetes, and Related Disorders in Asian Indians. Diab Tech Therap 13(6): 683-694.

9. Gray A (2015) Nutritional Recommendations for Individuals with Diabetes.

10. Schwingshackl L, Hoffmann G (2014) Monounsaturated fatty acids, olive oil and health status: a systematic review and meta-analysis of cohort studies. Lipids in Health and Disease 13: 154.

11. Evert AB, Boucher JL, Cypress M, Dunbar SA, Franz MJ, et al. (2013) Nutrition Therapy recommendations for the management of adults with diabetes. Diabetes Care 36(11): 3821-3842.

12. Wander S (2017) Lipid management in India: a nationwide, crosssectional physician survey. Lipids Health Dis 16: 130-139.

13. Feeney EL, O’Sullivan A, Nugent AP, McNulty B, Walton J, et al. (2017) Patterns of dairy food intake, body composition and markers of metabolic health in Ireland: results from the National Adult Nutrition Survey. Nutr Diabetes 7(2): e243.

14. Nelson KM, Reiber G, Boyko EJ (2002) Diet and exercise among adults with type 2 diabetes: findings from the third national health and nutrition examination survey (NHANES III). Diabetes Care 25(10): 1722-1728. 
(C) This work is licensed under Creative (C) Commons Attribution 4.0 Licens BY DOI: 10.19080/CRDOJ.2019.09.555769
Your next submission with Juniper Publishers will reach you the below assets

- Quality Editorial service

- Swift Peer Review

- Reprints availability

- E-prints Service

- Manuscript Podcast for convenient understanding

- Global attainment for your research

- Manuscript accessibility in different formats ( Pdf, E-pub, Full Text, Audio)

- Unceasing customer service

Track the below URL for one-step submission https://juniperpublishers.com/online-submission.php 